\title{
CARLOS YOUNGER DE LA PEÑA (1920-1996). "LA UROLOGÍA MADRILEÑA EN LA SEGUNDA MITAD DEL SIGLO XX"
}

\author{
Julio Antonio Virseda Rodríguez.
}

Jefe del Servicio de Urología. Complejo Hospitalario y Universitario de Albacete. Profesor Asociado de la Universidad de Castilla la Mancha. Albacete. España.

El artículo está dedicado a la familia Younger: Elena Pérez de Villamil de Younger y Elena Younger Pérez de Villamil.

Resumen.- Carlos Younger de la Peña (1920-1996) fue uno de los urólogos representativos en su época, tanto de la Urología en general como de la escuela madrileña en particular, durante los cuarenta años comprendidos entre 1945 a 1985.

Su formación profesional estuvo vinculada al Servicio de Urología del Hospital de la Princesa dirigido por el doctor Pedro Cifuentes Díaz y posteriormente por el doctor Luis Cifuentes Delatte. La importante influencia de la Urología francesa llevaría a Carlos Younger a completar sus estudios en los Servicios de Urología de los profesores J. Cibert (Lyon), Truc (Montpellier) y
Couvelaire (París). A su regreso de Francia realizaría su Tesis Doctoral con el título de "Estudio experimental de la Ureterosigmoidostomía según la técnica de Coffey I" dirigida por el profesor J. García Orcoyen en 1957. Sus primeras publicaciones comienzan en 1946 finalizando con cerca de las cien, incluyendo las comunicaciones a los distintos Congresos y Reuniones de la Especialidad.

Establecido en su Clínica particular de la madrileña calle de Ferraz alterna su práctica profesional entre los enfermos de la Seguridad Social y el Hospital Central de la Cruz Roja. Al final de su vida había recogido cerca de las 10.000 historias clínicas.

Perteneció a distintas Sociedades científicas / entre ellas la Internacional de Nefrología I y recibió diversos Premios como el de la Asociación de Cirujanos de la Infancia por su trabajo "Extrofia Vesical" y el de la Academia de Medicina de Valladolid por su estudio "Hipertensión Vasculorrenal".

En 1961 efectuaría el segundo homotrasplante renal en España.

Su interés profesional se centró preferentemente en la uro-oncología, la urología infantil, la urología ginecológica y la cirugía endoscópica. Dejaría numerosos discípulos con los mismos intereses.

La vida profesional de Carlos Younger de la Peña, en el periodo analizado, es muy significativa de la evolución de la Urología y de los urólogos durante medio siglo.

Palabras clave: Urología. Madrid. Carlos Younger. Historia de la Urología. 
Summary.- Carlos Younger de la Peña (1920-1996) was one of the representative urologists of his time, both in urology as a whole and particularly in urology in Madrid, during the 40 years between 1945 to 1985.

His professional training was linked to the department of urology in the "La Princesa" Hospital chaired by Dr. Pedro Cifuentes Díaz first and Luis Cifuentes Delatte posteriorly. The important influence of French urology led Carlos Younger to complete his studies in the departments of urology chaired by professors J. Cibert (Lyon), Truc (Montpellier) and Couvelaire (Paris). When he returned from France he completed his doctoral thesis with the title "Experimental study on the ureterosigmoidostomy type Coffey I" directed by Prof. J. Garcia Orcoyen in 1957. His first publications started in 1946 and he ended with almost 100, including communications to various speciality congresses and meetings.

Established in his private clinic in the Ferraz Street in Madrid he alternated his professional practice between Social Security patients and the Red Cross Central Hospital. At the end of his life he had collected near to 10.000 patients' clinical records.

He was member of various scientific societies lamong them the International Society Of Nephrologyl and received various awards such as the one from the Pediatric Surgeons Association for his work on "bladder exstrophy "and the one from the Medical Academy of Valladolid for his study "Vascular renal hypertension". In 1961 he performed the second renal transplant in Spain.

His professional interest was preferentially focused on uro-oncology, pediatric urology, gynecologic urology, and endoscopic surgery. He left many disciples with the same interests. The professional life of Carlos Younger de la Peña, in the period of time under analysis, is much significant as a reflex of the evolution of urology and urologists over half a century.

Keywords: History. Madrid. Carlos Younger. History of Urology.

\section{INTRODUCCIÓN}

El recuerdo de mi maestro Carlos Younger de la Peña representa una de las imágenes personales más emotivas de la Urología española y de sus protagonistas, en especial en Madrid, durante los últimos cincuenta años. La personalidad humana y profesional de aquellos hombres marcaría, sin saberlo entonces, gran parte de la propia trayectoria vital. El contribuir a que no caigan en el olvido quienes nos precedieron poniéndolos en el conocimiento de las nuevas generaciones de urólogos forma parte de nuestra responsabilidad ya que conforme vamos haciendo la vida $y$, consecuentemente haciéndonos menos jóvenes, la tendencia afectiva hacia nuestra historia aumenta, sin duda, porque todo el pasado acontecer, modo de obrar específicamente humano, constituye la más perfecta lección para la interpretación de nuestro presente y orientación hacia el futuro.

Conocí al doctor Carlos Younger de la Peña a principios de 1968 cuando yo cursaba el tercer año de Medicina en la Facultad de la Universidad Complutense y en su Hospital Clínico de San Carlos, ubicados ya en aquellos años en los campos de la Moncloa madrileña. Fui a visitarle junto con uno de sus más agradecidos pacientes (mi padre, a quien había intervenido en varios ocasiones por sus frecuentes litiasis úricas) para que orientara y aconsejara sobre mi futuro profesional. Su despacho de la calle Ferraz 80 estaba presidido por un óleo de San Jorge (en memoria de su hijo) y los numerosos libros eran lo más visible en la estancia destacando la bata blanca de un "Don Carlos" alrededor de la cincuentena, alto y recio dejando adivinar un fuerte temperamento, y no tardó en preguntarme sobre mis inclinaciones profesionales de futuro ¿̇cirugía o medicina $_{\dot{\imath}}$. Por la primera ya me orientaba desde las primeras disecciones anatómicas en el viejo caserón del Hospital Provincial y el magnetismo que me producían los quirófanos del Pabellón del Tórax en la Facultad de Medicina. ¿̇Te gustaría la especialidad urológica? y rotundamente contesté con un no. Bueno me dijo -pero mientras que completas la licenciatura podría conocer la urología y luego ya decidirás-. Sin apreciarlo mi camino se marcaba sin intuir en ese momento que en los casi cuarenta años siguientes no me dedicaría a otra cuestión profesional.

Precozmente el concepto vocacional resulta muy impreciso por lo que adquiere toda su influencia la personalidad atrayente del maestro. Y la vista de Carlos Younger era arrolladora desde la presencia caballeresca hasta la profunda y vehemente entrega que ponía en marcha ante cualquier circunstancia que le rodeara, todo ello en una enorme capacidad de trabajo que intentaba inculcar a su alrededor. Para quien no le conociera bien podría ser, mal entendida, una aparente arrogancia que no era sino el reflejo pudoroso de una gran nobleza de sentimientos y una innata bondad. Al fin y al cabo una poderosa humanidad que como tal no estaba exenta de aciertos y fracasos que nunca pasaron sin huella para una exquisita conciencia en el profundo amor hacia su entorno familiar y en la valentía para afrontar la gran tragedia que supuso la muerte precoz de su hijo y las decepciones con las que, una infinita mala suerte, le acompañaron durante muchos momentos de su vida. 


\section{Biografía en lo personal de Carlos Younger de la Peña}

Lo dejó escrito en la "Memoria" redactada con motivo de sus numerosas oposiciones profesionales "Nací en Madrid el 28 de abril de 1920, en la calle de Goya no 66, casa a la que todavía recuerdo habitualmente cuando con frecuencia paso por delante de ella y vienen las sensaciones de la infancia cuando empecé mi primera enseñanza en el colegio de Escolapios de la calle Hermanos Miralles, época que transcurrió desde que se es párvulo hasta llegar al llamado entonces "ingreso" que haría en el Liceo Francés hasta concluir el bachillerato pocos días antes de estallar la Guerra Civil de 1936". Colapso universitario que sufrieron las generaciones de entonces yugulando las inclinaciones universitarias y vocacionales de muchos. "La penuria económica, que en un porcentaje muy elevado de familias sufrieron cuando acabó la guerra, hizo que muchos hijos pensáramos en la carga que para los padres podía representar el coste de una carrera".

No obstante, y con un esfuerzo familiar compartido, Carlos Younger, se matriculó en la entonces Universidad Central de Madrid, en el llamado Ingreso Selectivo de la carrera de Medicina, era el año 1940. Fueron dos cursillos intensivos emprendidos y aprobados con ilusión y vocación creciente. "¡Qué hermosa sensación sentí cuando pasamos al viejo edificio de la calle Atocha, la Facultad de Medicina de San Carlos!". No era para menos ya que en aquellos muros estaba encerrada la docencia de los grandes maestros de la Medicina. Unos, los menos, aún permanecían allí y otros más habían pasado dejando estela de sabiduría y del buen hacer médico.

Durante los siguientes años de la carrera sería interno de la Cátedra de Anatomía (Profesor Dehesa) y ayudante de prácticas efectuando trabajos de disección e incluso dando alguna clase particular de la que obtuvo unos primeros ingresos económicos que ayudarían a los escasos medios familiares. También obtendría una de las becas que ofertaba el Ayuntamiento como ayuda para los costes de la carrera ya que su padre, hombre ya mayor, con modesta situación no podía costearle la carrera.

En los años 40 el profesorado de la Facultad de Medicina de Madrid dejaría un soberbio recuerdo hasta nuestros días. Los años de Patología Médica estarían a cargo de Fernando Enriquez de Salamanca quien a su vez era el Decano y Presidente de la Real Academia de Medicina. Las cátedras de Patología Quirúrgica con los Profesores Laureano Olivares y León Cardenal. La farmacología con Lorenzo Velázquez, la microbiología y Valentín Matilla, la fisio- logía con José María del Corral, Sanz (ocupando la cátedra del represaliado Tello), y otros insignes profesores como J.Botella, García Orcoyen, Gay Prieto, Bermejillo, Estella, Llombart, García Tapia, Laguna, Leonardo de la Peña, Vallejo-Nájera, Piga, Sánchez López, Palanca, Gil y Gil.... (1)

Pero volviendo a Carlos Younger que había conseguido ser alumno interno en la sala doce del Hospital Provincial dirigida por el internista Dr. Enrique Vega Vaca y en donde aprendería las bases de la medicina clínica tan necesaria para cualquier Especialidad médica o quirúrgica. Nunca olvidaría el recuerdo quirúrgico del profesor Laureano Olivares influyéndole para su posterior carrera como cirujano sin olvidar las dificultades de la época en la que la rapidez de las manos era mantenida por el "globito del Ombredanne".

En el mismo Hospital Provincial de Madrid y en el Servicio de Urología dirigido por el doctor Ángel Pulido Martín ( en sustitución de Isidro SanchezCovisa ) tomó sus primeros contactos con el "arte" de sondar y allí conoció el cistoscopio, armarle, desarmarle y limpiarle, así como la visión de las primeras nefrectomías y cirugías prostáticas (7). Recordaba como adjunto de dicho servicio al Dr. Enrique Pérez Castro. Fue para él una enseñanza corta pero, como toda enseñanza, útil y siempre fue recordada con gratitud y cariño.

"Y por fin, llegó la fecha de finalizar mi Licenciatura, corría junio de 1945. Hice la reválida con la calificación de sobresaliente, y posteriormente con la misma calificación las cuatro asignaturas necesarias del doctorado. Nunca creí que todo había concluido, y siempre pensando en el futuro, surgió la idea de hacer la Tesis Doctoral, e inclinado por la Cirugía, esta Tesis no podría versar más que sobre un tema exclusivamente quirúrgico". Pero aún habrían de pasar varios años más hasta conseguir este objetivo y obtener el grado de Doctor.

\section{La Urología de Carlos Younger de la Peña}

En los finales años cuarenta del pasado siglo XX la vocación urológica de Carlos Younger estaba bien definida al comenzar a asistir al Servicio de Urología del Hospital de la Princesa dirigido por el doctor Pedro Cifuentes Díaz, allí comenzaba su formación urológica.

"Surgió en mí la vocación quirúrgica, y por ello, antes de mi especialización definitiva, también creí necesaria, mi formación básica en Cirugía General. La suerte fue conocer al doctor Plácido González 
Duarte, en el mismo marco del Hospital de la Princesa, y allí aprendí la cirugía en las manos de un gran maestro. Posteriormente mi orientación se centró, ya para siempre, en la Urología dirigida por don Pedro Cifuentes Díaz en el mismo Hospital de la Princesa". (19).

En aquellos años, y casi seguidamente, salieron a concurso-oposición la Cátedra de Urología del Hospital Clínico, obtenida brillantemente por Alfonso de la Peña (1948), (9), (12), (13) la Jefatura del Servicio de Urología del Hospital Provincial, ganada por Enrique Pérez Castro, y, finalmente la Jefatura del Servicio de Urología del Hospital de la Princesa, adjudicada a Luis Cifuentes Delatte. Siempre Carlos Younger recordaba la brillantez de los candidatos en un marco de gran tensión entre los que apoyaban a unos o a otros. Época ya para siempre desaparecida y en la que públicamente había que demostrar los conocimientos y las actitudes personales en las demoledoras "trincas" en las que los opositores tenían voz para criticar, médicamente, al contrario en su "currículum". (8), (11).

"El Servicio de Urología del Hospital de la Princesa, que dirigía el Dr. Pedro Cifuentes Díaz a su vez Decano-Jefe del cuerpo facultativo de la Beneficencia General, me acogió con todo cariño y allí

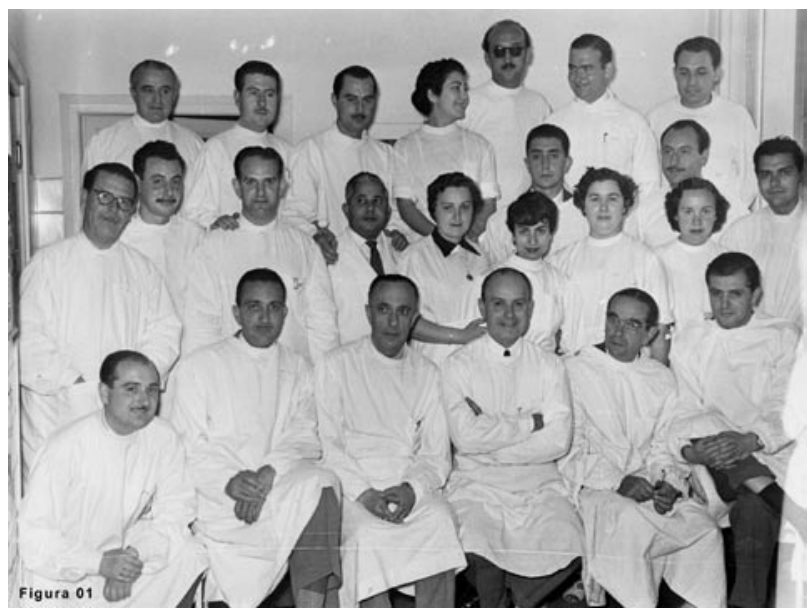

FIGURA 1. Servicio de Urología del Hospital de la Princesa (Madrid). Principios de los años 50 del Siglo XX. Al lado del Dr. Luis Cifuentes Delatte Uefe del Serviciol y a su derecha el Dr. Victoriano Molina, y a su izquierda del Dr. Alfonso Casas Motta. A la derecha de Victoriano Molina se encuentra Carlos Younger de la Peña. En la misma foto se puede reconocer al Dr. Andrés Sánchez Salvador y al Dr. Carlos Alférez entre otros. comenzaron mis primeros contactos con el enfermo urológico".

El 24 de julio de 1947 es nombrado Médico Interno de la Beneficencia General del Estado, siendo expedido y firmado el correspondiente título por el Ministro de la Gobernación Blas Pérez González. El sueldo anual era de cinco mil pesetas. Hasta 1951 el sueldo anual no alcanzaría las seis mil pesetas.

Entre los finales de los años cuarenta y principios de los cincuenta "viví los años de formación urológica en todas las secciones. El laboratorio, la radio-urología y el quirófano. En definitiva la base de mi formación". (Figura 1).

A partir de 1946 aparecen las primeras publicaciones de don Carlos: "Sección total del riñón por traumatismo" (1946), "Estudio clínico de las hematurias" $\mathrm{y}$ "El tratamiento de las retenciones vesicales de orina" (1949), "lleo paralítico reflejo, como síntoma cardinal de un riñón poliquístico" y "Cálculo vesical intradiverticular gigante" (1950), "Gran quiste seroso solitario del riñón", "Cuatro observaciones de leucoplasia de la pelvis renal" y "Quiste hidatídico renal" (1951), "Disfunción vesical neurógena, tratada por resección de los nervios presacros e hipogástricos" (1952).

La formación francesa de Pedro Cifuentes Díaz influyó en el nuevo urólogo aceptando que la Urología del país vecino, $y$, desde los tiempos de $F$. Guyón, J. Albarrán, F. Legueu, G. Marión... y otros grandes maestros ha sido la cuna de esta Especialidad, dando lugar a las grandes Figuras de aquellos momentos: R. Couvelaire, J. Cibert, E. Truc, R. Küss entre otros. "El deseo de superación produce intranquilidad, y, ¿̇ porqué no debía intentar superar mi formación urológica, con enseñanzas complementarias de lo que estaba viviendo?". Carlos Younger asistiría, con beca del Gobierno francés, al Servicio de Urología dirigido por el profesor Jean Cibert en el hospital Edouard Herriot de Lyon. "Allí es donde me di cuenta de que la cirugía no era solo extirpar sino también sustituir. Las extirpaciones vesicales podían ser seguidas de su sustitución por medio de un segmento intestinal aislado (ileo y colocistoplastias de ampliación o de sustitución vesical)". En los años siguientes (1952) asistiría a la clínica San Carlos de Montpellier dirigida por E. Truc, y, posteriormente en el Hospital de la Facultad de Medicina de París (Hospital Saint Louis) dirigida por R. Couvelaire.

Con la enseñanza de los grandes maestros la Urología se desarrollaba rápidamente en nuestro país desde finales de los años cincuenta. Ya no se trataba de extirpar un riñón, sino de conservarlo, o 
en el caso de la exéresis vesical que condenaba al enfermo a una derivación urinaria haciendo penosa su vida sino de sustituirla por una nueva vejiga intestinal, ileal o cólica, permitiendo la micción por vías naturales y recuperando al enfermo para la sociedad. Las indicaciones de extirpación del adenoma prostático valoraban la posibilidad de cirugía transuretral como alternativa a las clásicas vías hipogástricas de Freyer o de Marión, las perineales o la entonces recién implantada técnica retropúbica y transcapsular de $\mathrm{T}$. Millin. Las mismas lesiones ureterales, con frecuencia en riñón único después de la nefrectomía contralateral por TBC, permitían su reparación a través de las distintas ureterocistoneostomías directas tipo Puigvert o a través de colgajos vesicales tipo Boari-Küss. (2-6).

Por otra parte, comienza al lado de la cirugía, una Especialidad, que era la moderna anestesia y los diversos pioneros (Elío, Llauradó, Vela...) se trasladan a Escocia al lado del maestro Mc Intosch y vuelven a España con los nuevos fármacos anestésicos, relajantes musculares y la consolidación de la intubación endotraqueal. Las nuevas técnicas de esta Especialidad producen en los cirujanos un gran impacto, ya que el riesgo quirúrgico disminuye y ya es posible la gran cirugía con inesperados éxitos como resultado de la inter colaboración entre anestesistas y cirujanos. "Un buen cirujano se merece un buen anestesista y un cirujano mediocre le necesita", era la frase de la época.

Un problema quirúrgico de la época eran las frecuentes estenosis de la anastomosis en las ureterosigmoidostomías (22-23), como consecuencia de la formación de un granuloma inflamatorio en la clásica técnica de Coffey. Otra alternativa de anastomosis ureterosigmoidea era en "valvas" tipo Payne y que se difundió en nuestro país a través de Luis Cifuentes. Así se realizó la Tesis Doctoral de Carlos Younger "Estudio experimental de la Ureterosigmoidostomía según la técnica de Coffey I". En el año 1957 no fueron pocas las dificultades de la cirugía experimental en el perro a pesar de realizarse en la Escuela de Veterinaria. Este trabajo de Tesis no se desarrolló en ninguna Cátedra Quirúrgica ya que Carlos Younger permaneció fiel al maestro y al Servicio de Urología donde se desarrollaba su formación y este era Pedro Cifuentes Díaz y su Servicio de Urología en el madrileño Hospital de la Princesa. El presidente del Tribunal para la Tesis fue el profesor García Orcoyen y los otros miembros fueron los profesores Lafuente Chaos, Martín Lagos,Botella Llusiá y Alfonso de la Peña Pineda. La calificación fue de sobresaliente por unanimidad optando al Premio de la Real Academia de Cirugía de Madrid y no concediéndose por no haberse realizado el estudio en el marco de una Cátedra universitaria. "No obstante me encontraba muy orgulloso de que la idea y la orientación surgieran en el Servicio de Urología del Hospital de la Princesa y del propio doctor Pedro Cifuentes Díaz".

En los años siguientes se suceden las publicaciones de Carlos Younger destacando su interés por los tumores génito-urinarios: "Neoplasias malignas renales" (1953), "Tumores de testículo" (1954), "Tumor gigante paranefrítico" (1958), "Tumor raro renal. Adenocarcinosarcoma" (1961), "Carcinoma renal (cáliz superior)" (1962), "Observaciones de células neoplásicas en sangre periférica en un caso de carcinoma renal" (1963). Así como su colaboración con la Ginecología : "Divertículos de la uretra femenina: Dos casos" (1953), "Otro caso de divertículo uretral femenino" (1960), "Hipertrofia del cuello vesical en la mujer" (1962). Otro campo de interés sería el de la Urología Infantil "Cistectomía Parcial por Megavejiga" (1954), "Falso tumor retroperitoneal (absceso perisigmoideo). Crisis de cólicos nefríticos en un niño de tres años" (1955), "Torsión de la hidátide pediculada de Morgagni" (1957), "Extrofia vesical" (1963), "Tumores renales malignos en la infancia" (1970).

A principios de los años 60 también evolucionan otras Especialidades y no se olvida la parte puramente médica de la Urología: la Nefrología con Figuras pioneras como Sánchez Sicilia, Hernando, Botella, Valderrábano, María Teresa D' Ocón, Gerardo del Río, Caralps, Rotellart ... etc. Entre las publicaciones de Carlos Younger se cuentan en este sentido "Las anurias. Su tratamiento" (1953), "Albuminuria Ortostática" (1955), "Nefropatías unilaterales" (1962), "Los corticoesteroides en Urología y Nefrología" (1970).

Por otra parte los nuevos medios diagnósticos permitieron el perfecto conocimiento de la Urología Infantil, ya perfectamente establecida por los urólogos conocedores tradicionalmente de esta patología tal como Campbell en los Estados Unidos y Innes Williams en Inglaterra. Ello permitió en la década de los 60 las modificaciones técnicas que actuaban sobre las malformaciones congénitas del aparato génito-urinario infantil: extrofias vesicales, hipospadias, epispadias con posibilidad de la recuperación funcional y anatómica de los órganos afectos. Los megauréteres, las hidronefrosis congénitas, las válvulas uretrales, el reflujo vésico-ureteral..., toda una patología urológica capaz de producir a distancia graves alteraciones renales. Las nuevas técnicas de urografía intravenosa, cistografías, endoscopios infantiles, resectores en "miniatura" permitieron un diagnóstico exacto y en consecuencia, con la técnica quirúrgica adecuada, evitar el daño irremediable e irreversible de los riñones $(15,18)$. 
Consecuencia del interés de Carlos Younger y de sus colaboradores de aquellos años por la Urología Infantil fueron las numerosas intervenciones quirúrgicas en el Servicio de Cirugía Pediátrica que dirigía en el madrileño Hospital del Niño Jesús el doctor Juan Garrido Lestache, uno de los pioneros de la cirugía infantil en nuestro país. Simultáneamente, y en estos años 60, Younger redactó la monografía sobre "Extrofia Vesical" (1963) mereciendo el Premio de la Sociedad Española de Cirujanos de la Infancia. Al año siguiente su colaborador el doctor Eduardo Chacón mereció el mismo galardón con su trabajo "Malformaciones Congénitas del Aparato Urinario Superior". Pasarían muchos años hasta que el firmante de este artículo consiguiera enlazar con esta tradición a través del trabajo "Litiasis Urinaria Infantil" de 1973.

Carlos Younger después de los años de formación en el Hospital de la Princesa, la ampliación de estudios en varios hospitales franceses y finalizar la Tesis Doctoral ya tiene la confianza de sus pacientes y entre ellos don Jacinto Benavente (Figura 2) escribe "surgió en mí la idea de fundar una Clínica de Urología donde fuera posible el completo diagnóstico de los pacientes a través de todos los medios técnicos utilizados hasta el momento". Ello no debía impedir el contacto con el medio hospitalario donde los enfermos, de diversas procedencias, eran intervenidos por un Equipo de colaboradores dirigidos por Carlos Younger en el Hospital de la Cruz Roja.

\section{La Clínica de Urología de Ferraz 80. Madrid}

Era un amplio piso en las cercanías del Parque de Oeste entre el Paseo del pintor Rosales y la calle Marqués de Urquijo. Disponía de varios despa-

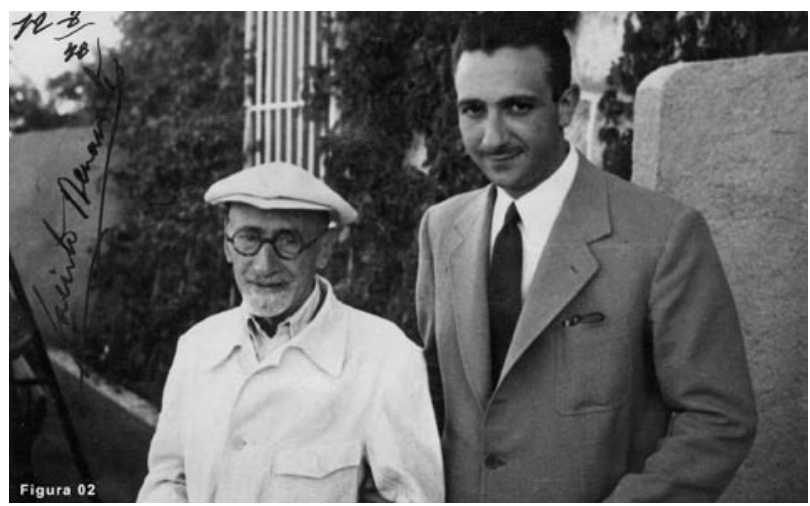

FIGURA 2. El Dr. Carlos Younger de la Peña con su paciente D. Jacinto Benavente. Galapagar (Madrid), 1948. chos médicos, gabinete de radiología, sala de cistoscopias, biblioteca, archivos varios incluyendo el importante de bibliografía, museo anatomopatológico, laboratorio y una pequeña sala donde se efectuaba la cirugía experimental en el perro (cirugía intestinal y técnicas de sutura vascular).

Era allí donde se realizaba el estudio diagnóstico completo del enfermo urológico de la época. El laboratorio, a cargo del doctor López Salcedo realizaba desde el sencillo sedimento urinario (siguiendo las ideas de Luis Cifuentes) hasta los estudios de bioquímica sanguínea, urocultivos y antibiogramas... etc. La radiourología con el doctor Vicente Barrios incluía la urografía intravenosa, pielografías instrumentales, cistografías, uretrografías, las pielografías percutaneas (publicadas en 1969 "Técnica radio-urológica: Pielografía percutanea"), y unas rudimentarias arteriografías renales con la recién incorporada técnica de Seldinger. A lo largo de más de veinticinco años se realizarían más de diez mil placas radiográficas y de ellas las muy demostrativas quedarían rigurosamente archivadas en su correspondiente fichero radiográfico. Al mismo tiempo en cada historia clínica se incluía una copia radiográfica en papel o en negativo lo que facilitaba la valoración del enfermo en sucesivas revisiones. El trabajo fotográfico se realizaba en la misma Clínica al disponer de un pequeño estudio o en la Clínica de la Concepción y su fotógrafo D. Guillermo del Olmo (10).

Disponíamos de un museo anatomopatológico con alrededor de trescientas piezas quirúrgicas perfectamente recogidas y preparadas en sus correspondientes envases por el que fuera mozo de la Cátedra de Anatomía del profesor Gómez Oliveros. El fichero con numerosas preparaciones histológicas se conservaba cuidadosamente ordenado y archivado con la colaboración del profesor Escalona Zapata.

No podía faltar, igual que hoy, una sala de cistoscopia para el estudio de la diversa patología vesical primaria o secundaria a otros procesos del aparato génito-urinario. Frecuentemente el artista y pintor Ladislao Tinao recogía en perfectos dibujos lo observado a través del cistoscopio acumulàndose una experiencia de más doscientas láminas endoscópicas. El dibujo y la ilustración médica alcanzó altísimos nivelas en estas circunstancias ya que igualmente y en el quirófano se recogieron más de 2000 apuntes que posteriormente se trasladaban a todo color. Una selección de estas láminas quirúrgicas fueron publicadas por mí en el "Atlas llustrado de Cirugía Urológica" (2004) (Figuras 3 y 4).

Simultáneamente y en una pequeña sala se practicaba periódicamente la cirugía experimental 


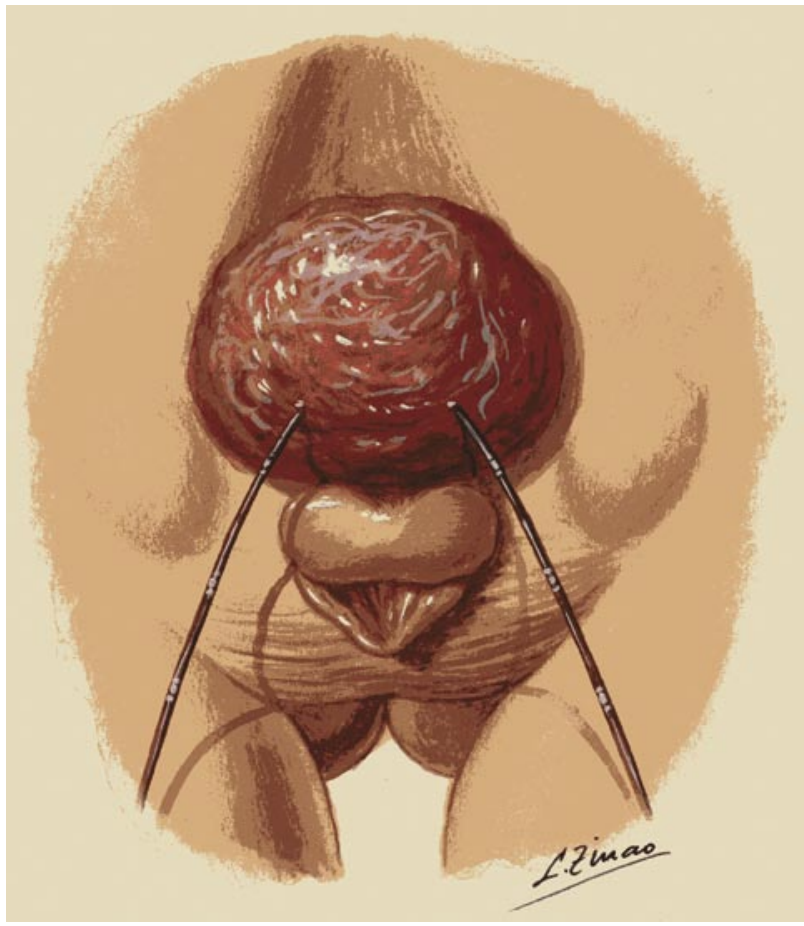

FIGURA 3. Dibujo de una extrofia vesical en un niño de pocos meses de edad y realizado por D. Ladislao Tinao, tomado del natural.

en el perro efectuándose numerosos trasplantes renales como paso previo a la puesta en marcha del procedimiento en el humano ("Autotrasplante Renal en el perro. Estudio experimental" (1961). También se hicieron protocolos de cirugía intestinal experimental, previos y simultáneos, a las entonces frecuentes, ileo y colocistoplastias de ampliación en las "pequeñas vejigas" tuberculosas (Figura 5).

La pasión por la enseñanza llevó a Carlos Younger a filmar varias docenas de películas quirúrgicas de las diversas técnicas novedosas del momento.

La Biblioteca de la Clínica disponía de un abundante material de libros de la Especialidad, desde los clásicos como joyas del pasado, hasta los novedosos. La Urología francesa estaba representada desde F. Guyón, J. Albarrán, A. Pousson, E. Desnos, E. Papin, F. Legueu, G. Marion, B. Fey, J. Cibert, R. Couvelaire o R. Küss entre otros. En la cada vez más influyente urología norteamericana las obras de H. H. Young, O. S. Lowsley, H.C. Rolnick, A. I. Dodson, R. Nesbit, O. Baumrucker, V. F. Marshall, M. F. Campbell, H. M. Weyrauch, Hutch. Dentro de la Urología británica disponíamos de las obras de Thompson, H. Morris, J. Thomson-Walker, J. Swinney,

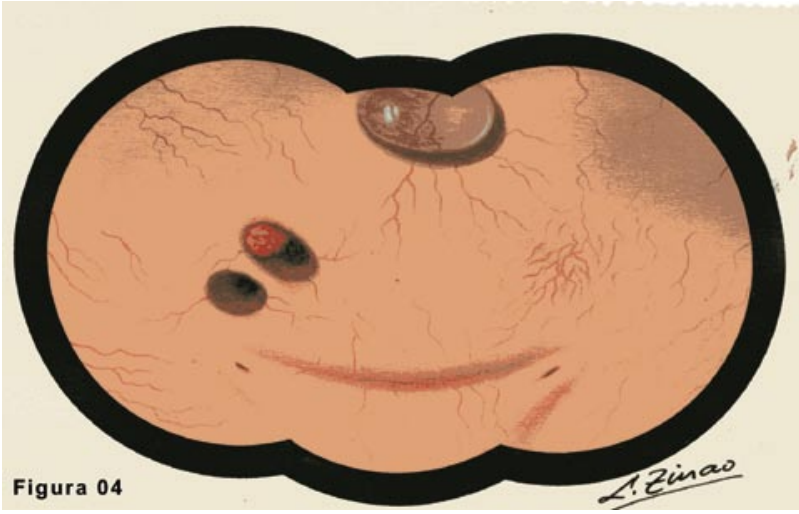

FIGURA 4. Dibujo cistoscópico realizado por

D. Ladislao Tinao y tomado en pocos segundos de observación cistoscópica.

E. W. Riches, G. D. Chisholm, T. Millin, J. Blandy, Turner-Warwick...

Mención especial merecen las monografías y tratados parciales de la Urología española con nombres como Pedro Cifuentes Díaz, Luis Cifuentes Delatte, Alfonso de la Peña, Antonio Puigvert, Salvador Gil Vernet y José María Gil-Vernet Vila, Julio Picatoste y Patiño, José María Bartrina, Luciano Azagra, Rafael Alcalá Santaella, Salvador Pascual... etc. (16-17).

No faltaban en la Biblioteca los libros de "Enfermedades Renales" y que posteriormente a partir de principios de los años sesenta del siglo XX se conocerían como "Nefrología" (no sin razón Carlos Younger era Miembro de la Sociedad Internacional de Nefrología presidida por J.P. Merrill y como Secretario General J.L. Funck-Brentano. ). El Tratado de Nefrología de Jean Hamburger presidía la sección de libros de este tema.

Todos ellos libros de emotivo recuerdo ya que fueron nuestras primeras lecturas urológicas marcando gran parte de la vida profesional durante los siguientes cuarenta años (20-21).

En otro aspecto la cirugía de Carlos Younger de la Peña estaba caracterizada por la rapidez brillante de la época (Figuras 6 y 7). La cirugía de la litiasis (hoy prácticamente sustituida por otros procedimientos) se repartía entre la frecuente Pielolitotomía simple o combinada con diversas nefrotomías hasta la gran nefrotomía longitudinal posterior (después llamada anatrófica), la nefrectomía parcial (basada en los conceptos de papilitis litogénica de Puigvert). Al igual que las distintas ureterolitotomías (14). 


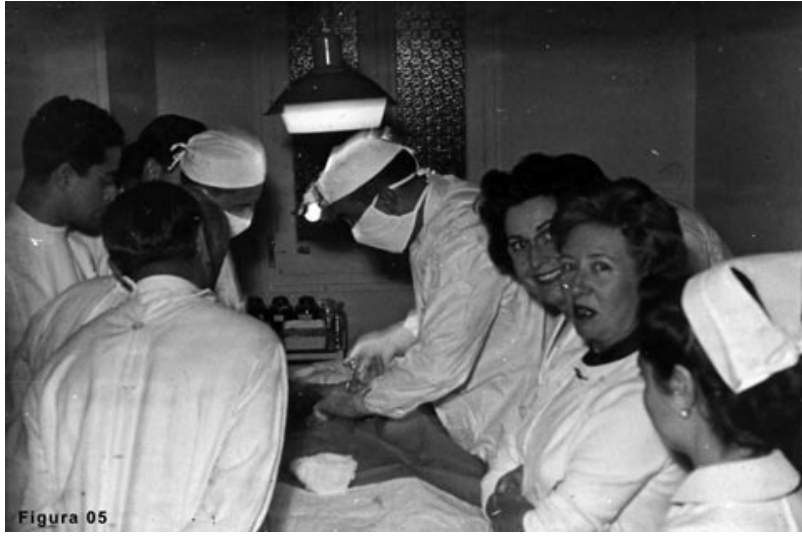

FIGURA 5. Pequeño quirófano para cirugía experimental en la Clínica de Ferraz 80 (Madrid). Carlos Younger realizó numerosos autotrasplantes renales en el perro así como cirugía intestinal.

La otra patología de los años sesenta, ocupando una parte importante del trabajo quirúrgico, era la Tuberculosis urinaria y genital y la necesidad de Nefrectomía (diferida) o de cirugía conservadora a través de las Nefrectomías Parciales (Semb, Ljungren, A. Puigvert) o las cavernostomías (Staehler, J. $M^{a}$ Gil-Vernet). En la estenosis específica del uréter distal era utilizar la Ureterocistoneostomía en valvas difundida por Puigvert. La "microvejiga" tuberculosa era ampliada con diversas plastias intestinales de ileon o de colon (Scheele, Couvelaire, Cibert, J. $M^{\mathrm{a}}$ Gil-Vernet ).

El cáncer de vejiga superficial, en los años 60 del siglo pasado, ya se beneficiaba ampliamente de la resección transuretral y en nuestro caso siguiendo los caminos abiertos por la escuela de Luis Cifuentes después de regresar de su estancia norteamericana y haber conocido a los grandes maestros norteamericanos de la cirugía transuretral (Nesbit, Flocks, Alcock...) y publicar su libro en 1961. Aunque sin olvidar que ya en 1944 Alfonso y Emilio de la Peña y también después de regresar de las clínicas norteamericanas (Clínica Mayo en el caso de don Alfonso y San Francisco en el caso de Emilio) habían dado a conocer la técnica de cirugía transuretral especialmente el "punch" de Thompson y Braasch lambos expertos cirujanos endoscopistas de la citada Clínica Mayo). La pugna entre ambas escuelas era entre uno $u$ otro procedimiento y solo el tiempo dejaría las cosas en su lugar. Por otra parte el cancer vesical infiltrante o el superficial extenso no controlable se trataba con cistectomía total, bien por vía transperitoneal de Brunschwig, Marshall, Leadbetter, Proust... o por vía extrapertitoneal de Couvelaire, Millin. La derivación urinaria más utilizada era la ureterosig-

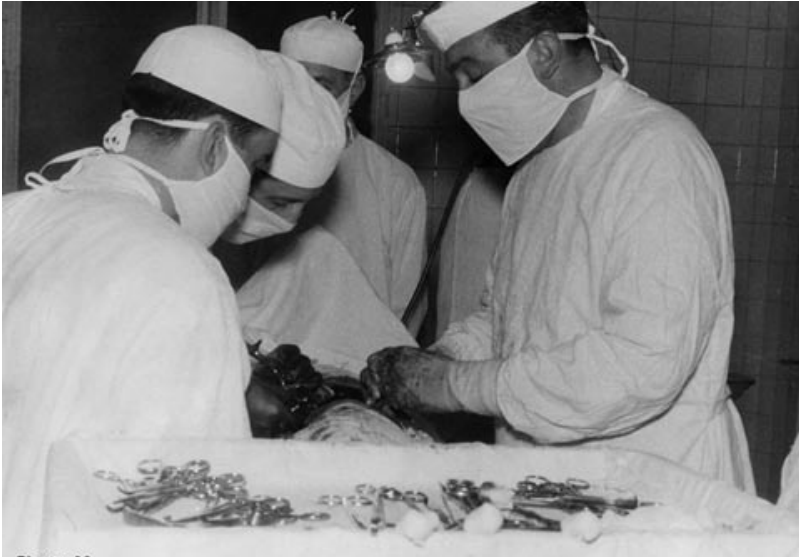

FIGURA 6. Quirófano de Carlos Younger hacia mitad de los años 50 del siglo XX. Probablemente se trata del Sanatorio del Rosario (calle Príncipe de Vergara (Madrid).

moidostomía o la ureterostomía cutane. A principios de estos años 60 comenzó a difundirse en España la Ureteroileostomía cutánea de Bricker, y en Madrid al menos por J. A. Martínez Piñeiro. Por el contrario en

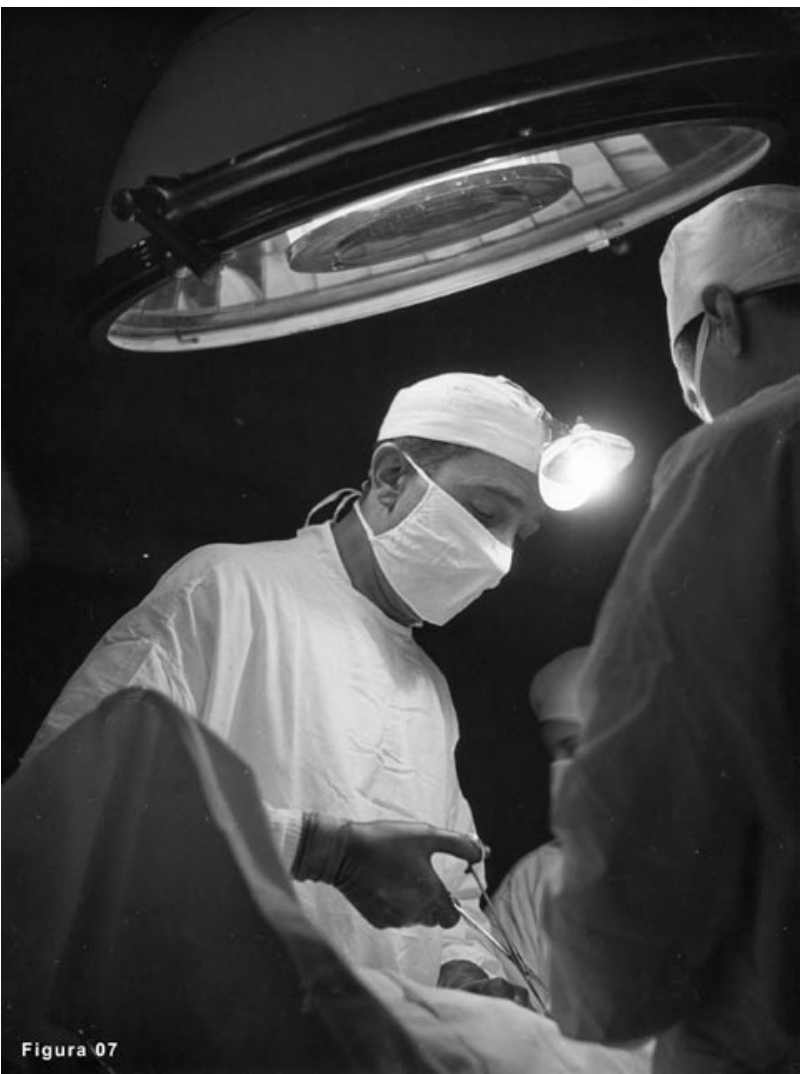

FIGURA 7. Carlos Younger en el quirófano (finales de los años 50). 
Barcelona J. $M^{a}$ Gil-Vernet defendía, como alternativa a la ureterosigmoidostomía, la completa sustitución vesical por un segmento intestinal aislado. La transuretero-ureterostomía cutánea de Higgins (1934) y Obrandt (1957) eran poco utilizadas en el medio de Carlos Younger. En 1962 llegó una de las primeras quimioterapias intravesicales con el Thio-tepa difundido por Veenema en los Estados Unidos.

El panorama quirúrgico de los 60 se ampliaba al no tener ya las fronteras que se imponían las generaciones anteriores: la pleura y el peritoneo, y en este sentido a Younger le resultaría muy útil el tiempo de estancia al lado de la Cirugía General con el doctor Plácido González Duarte. Desde las vías limitadas como la lumbotomía vertical posterior de Simon hasta los abordajes transperitoneales tipo Poutasse, o torácicos como los accesos tóraco-abdominales tipo Fey o Nagamatsu.

La cirugía del adenoma prostático se mantenía en la fidelidad de la vía suprapúbica transvesical con hemostasia selectiva de la celda prostática. Sonda uretral gruesa tipo Couvelaire sin taponamientos de celda prostática y sin lavados continuos que no fueran los frecuentes lavados vesicales a cargo del personal de enfermería (Figura 8).

\section{Carlos Younger y el segundo Homotrasplan- te Renal en España (1961)}

El 7 de febrero de 1961 se efectuaba, por Carlos Younger y un numeroso equipo de colaboradores, el segundo homotrasplante renal en España

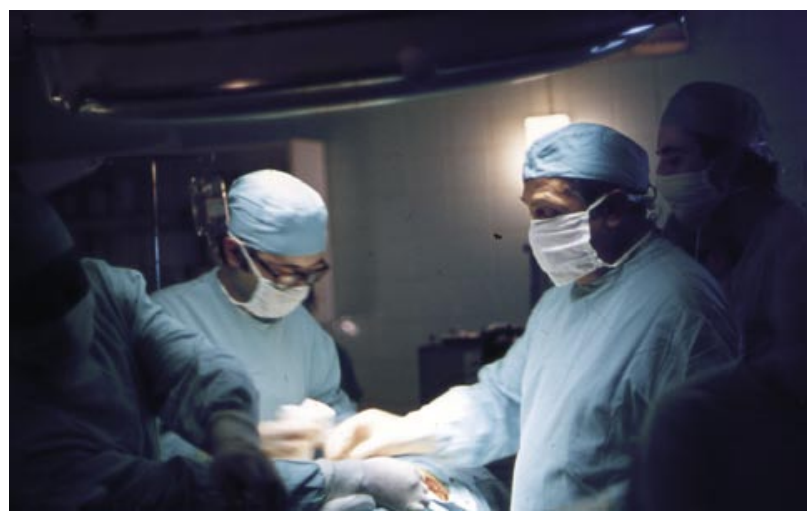

FIGURA 8. Carlos Younger en el quirófano del Hospital Central de la Cruz Roja. En la misma foto Julio A. Virseda, Pablo Virseda y el estudiante guineano Jesús García Ribala.
( unos meses antes el doctor José Antonio MartínezPiñeiro había realizado el primero).

El receptor (Antonio F.) de 30 años de edad era portador de un riñón único derecho por una agenesia renal izquierda. Durante los once años previos el único riñón había sido sometido a varias intervenciones quirúrgicas por un diagnóstico inicial de pionefrosis secundaria a un uréter retrocavo: drenaje de absceso perirrenal, nefrostomía derecha, reparación quirúrgica de ureter retrocavo, ureterolitotomía ilíaca, ureterolitotomía lumbar y nefrolitotomía simultanea.

A principios de 1960 el paciente se encontraba en una situación de insuficiencia renal crónica irreversible. "Nos encontramos ante una situación desesperada sin ninguna posibilidad de tratamiento. Fueron entonces el mismo enfermo y su familia los que nos indicaron, influidos por las noticias de la prensa, la posibilidad de un trasplante renal, para lo cual se ofrecían todos ellos. Como es natural, acogimos la propuesta con gran escepticismo. Conociendo nuestros límites en el campo que íbamos a introducirnos, era necesario ponernos en comunicación con las personas que conceptuábamos de experiencia, clínica o experimental, sobre trasplantes para que nos hiciera valorar el conjunto de condiciones inherentes a dicho tratamiento, al mismo tiempo que serían consultados los aspectos jurídicos y morales del problema".

El estudio inmunológico del donante (el padre del enfermo) y receptor fue realizado en Madrid (Doctores Elósegui y Ros de Saldaña) así como en el Instituto Lister de Londres (Dr. Race) demostrando la identidad de los grupos sanguineos: A, Rh positivo (se acababa de descubrir la utilidad del sistema HLA por Jean Dausset).

Al iniciarse febrero se inició la hospitalización del donante y del receptor en la madrileña clínica de Ntra. Sra. de la Paloma (Dr. Azcona). La inmunosupresión del momento consistió en la radioterapia total del receptor (Dr. Arce) hasta conseguir la aplasia medular procediéndose entonces al trasplante de médula ósea del donante al receptor. La intervención quirúrgica fue efectuada a las 12 de la noche del día 7 de febrero de 1961 y en dos quirófanos contiguos. Los doctores Carlos Younger, Eduardo Chacón y A. Hidalgo efectuaron la nefrectomía derecha del donante consiguiendo un pedículo vascular de unos $4 \mathrm{~cm}$. Extraído el riñón se procedió a su perfusión intra-arterial con suero fisiológico heparinizado al $3 \%$ (Dr. Parra). El órgano se mantuvo en hipotermia de superficie con hielo a una temperatura de 14-16․ El tiempo de isquemia fría fue de 15 minutos. En el quirófano receptor (Drs. R. Rivera, E. Chacón, Serrano y Fuentes) se procedió a situar el riñón en la fosa 
ilíaca derecha y proceder a la sutura vascular entre la arteria renal y la arteria hipogástrica en términoterminal, y la corta vena renal a la vena ilíaca externa en término-lateral. A continuación se efectuó una ureterostomía cutanea.

En el inmediato postoperatorio el riñón trasplantado no obtuvo diuresis por lo que a las 24 horas de la primera intervención se efectuó una revisión quirúrgica que demostró la integridad anatómica y vascular del injerto. Al cuarto día aparecieron hemorragias múltiples debidas a la plaquetopenia de la aplasia medular que llevaron a la muerte del paciente al $8^{\circ}$ día postoperatorio.

Como dato histórico de la época referida se efectuaron las siguientes consultas médicas antes de efectuar el trasplante renal, por Carlos Younger: en visita personal (profesor Hamburger en el Hospital Necker de París, profesor Delinotte en el Hospital Saint Louis de París, profesor Carlos Jiménez Díaz de la Clínica de la Concepción de Madrid). Y en correspondencia: Dr. G. Mathé (Hospital de Saint Louis en París), Drs. Robert y Ruth Race (Lister Institute de Londres), Dr. M.Boldini (New England Center Hospital de Boston) y Dr. Dammin (Peter Bent Brigham Hospital de Boston).

El estudio fue comunicado en la Mesa Redonda que sobre Trasplante Renal se efectuó en Barcelona en el mes de abril de 1961 asistiendo a dicha Mesa como componentes los Drs. Simonssen (Dinamarca), R. Küss y G. Mathé (París), Rotellar y Viñal (Barcelona). Al mismo tiempo se presentó en la

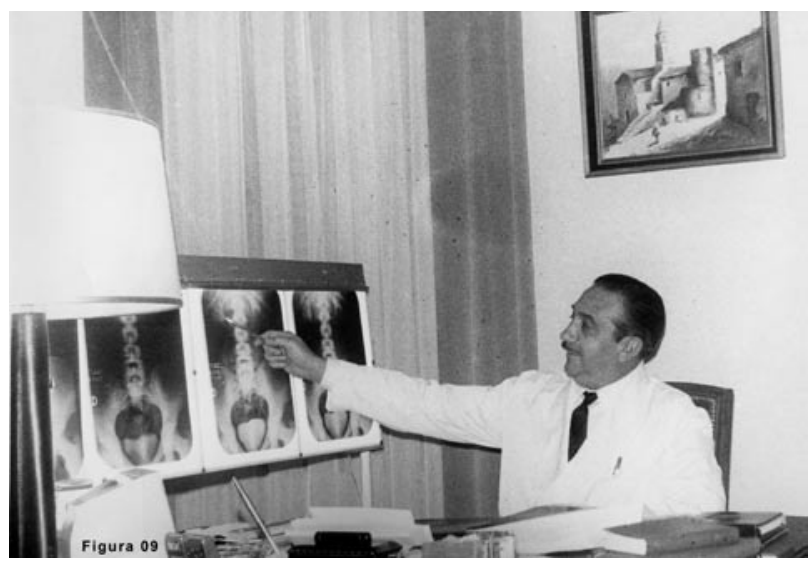

FIGURA 9. Carlos Younger en su despacho de la Clínica de Urología Ferraz 80 la principios de los años 60).
Reunión Anual de la Asociación Española de Urología en Valencia (mayo 1961) junto con el caso del doctor J. A. Martínez-Piñeiro. Posteriormente sería publicado en el Journal francés de Urología (Transplantation rénale (homotransplantation entre père et fils) pour grave insuffisance fonctionelle $d$, un rein unique congénital) (1962) y Problémes vasculaires des transplantations rénales (1962, Journal d,Urlogie et Nephrologie).

El caso clínico de Carlos Younger y el trasplante renal generaría una cierta polémica en su época y el entonces catedrático de Urología y Presidente de la Comisión Deontológico de los Colegios de Médicos profesor Alfonso de la Peña expresaría su desacuerdo y crítica con el procedimiento utilizado. Pero el camino del trasplante renal estaba abierto por sus pioneros y ya nada podría frenarlo.

Finalmente la vida de Carlos Younger de la Peña, le permitió ser Miembro de la Asociación Francesa de Urología (1951), Asociación Española de Urología (1954), Asociación Española de Cirujanos de la Infancia (1963) y Vicepresidente de la misma en 1972, Sociedad Internacional de Nefrología (1967), Académico de la Real Academia de Medicina y Cirugía de Valladolid (1973) y de la Academia Médico-Quirúrgica española (1978) (Figura 9).

Su interés personal por la Urología Pediátrica le permitió escribir la monografía "Extrofia Vesical y su tratamiento" siendo merecedora del Premio de

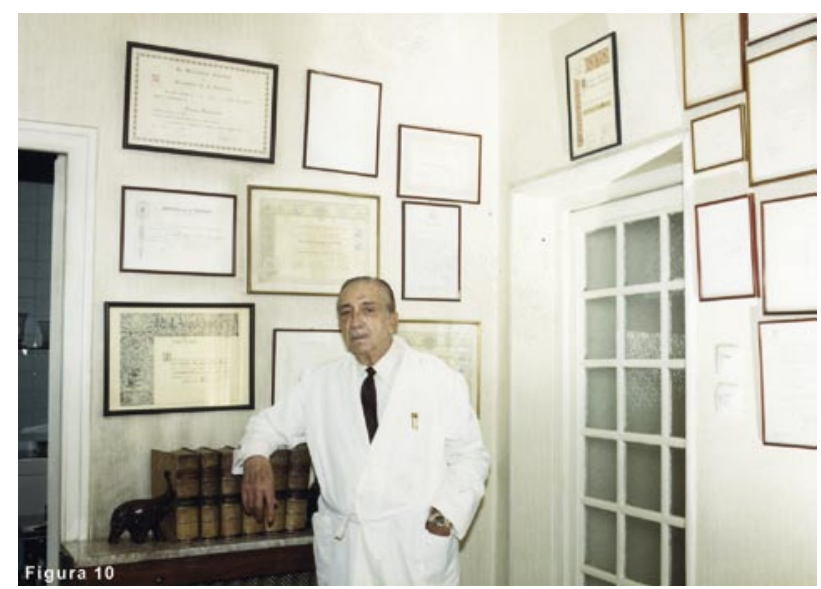

FIGURA 10. Carlos Younger en los años 90. Despacho de la consulta de Ferraz 80

El brazo derecho se apoya sobre los tomos de la Enciclopedia Médico-Quirúrgica francesa de principios del siglo XX. En las paredes numerosos títulos obtenidos durante su vida profesional. 
la Asociación Española de Cirujanos de la Infancia (1963). Su trabajo monográfico sobre "Tratamiento de la Hipertensión Reno-Vascular" fue Premio de la Real Academia de Medicina y Cirugía de Valladolid en 1973.

El conjunto de sus publicaciones y comunicaciones urológicas alcanzaría la cifra de 98 artículos. (ANEXO 1)

Sus plazas profesionales después de sus años en el Hospital de la Princesa serían la de Médico Especialista de Urología de la Seguridad Social en Madrid 1972 y Consultor del Hospital Central de la Cruz Roja desde 1976.

Al final de su vida Carlos Younger había recogido cerca de las 10.000 historias clínicas, de ellas alrededor de 500 de Urología Infantil, 5.000 placas en el archivo radiográfico, 300 piezas quirúrgicas en el museo personal anatomopatológico, 2.000 diapositivas (intervenciones quirúrgicas, piezas anatómicas, radiología, anatomía patológica, cirugía experimental...), más de 15.000 fichas bibliográficas, doce grandes tomos con los dibujos operatorios y endoscópicos de Ladislao Tinao (Figuras 8 y 9). El total de intervenciones quirúrgicas efectuadas por Carlos Younger (rigurosamente recogidas en el correspondiente dietario quirúrgico) alcanzaban el número de 7.654 .

Pero no sólo la vida personal y profesional de Carlos Younger está rodeada de hechos sino también de los Urólogos que rodearon a su generación y en consecuencia, con las distancias en años correspondientes, a los que fuimos sus discípulos y colaboradores más cercanos en periodos diferentes (Victorino Anllo, Eduardo Chacón, Fernando Sánchez Carreras, José Antonio García Estévez, Lorenzo Perales, Julio A. Virseda, Fernando Cano, Carlos Segovia, Pedro Sánchez de la Muela, Ortiz de Mendivil, Manuel Carbonero, y los ATS Felipe Solórzano, María, Pilar, $M^{a}$ Jesús, Joaquín Rodríguez, y seguramente algunos más que no recuerdo).

En resumen la vida profesional de Carlos Younger de la Peña entre los años 40 y 90 del siglo $X X$ es muy representativa de la evolución de la urología y de los urólogos durante medio siglo.

Carlos Younger fue pionero, junto con otros, de nuestra práctica profesional actual, aunque un cierto cansancio denote una de las últimas fotografías que se le tomaran en su despacho de la madrileña Clínica de Ferraz 80 (Figura 10 ).

\section{ANEXO I}

\section{Publicaciones del Dr. Carlos Younger de la Peña (1946-1981)}

1. Sección Total del riñón por traumatismo.

Revista Española de Cirugía. 1946

2. Estudio Clínico de las Hematurias.

Medicina. 1949

3. El tratamiento de las retenciones vesicales de orina. Medicina. 1949

4. lleo paralítico reflejo, como síntoma cardinal de un riñón poliquístico.

Arch. Esp. Urol. VI, 2. 195

5. Tratamiento del cólico nefroureteral.

Medicina. 1950

6. Cólico nefroureteral.

Medicina. Junio 195

7. Cálculo vesical intradiverticular gigante.

Arch. Esp. Urol. VI, 4. 1950

8. Gran quiste seroso solitario del riñón.

Arch. Esp. Urol. VII, 4. 1951

9. Cuatro observaciones de leucoplasia de la pelvis renal.

Arch. Esp. Urol. VII, 4. 1951

10. Quiste hidatídico renal.

Arch. Esp. Urol. VII, 4. 1951

11. Disfunción Vesical Neurógena tratada por resección de los nervios presacro e Hipogástricos.

Arch. Esp. Urol. VII, 1. 1952

12. Perinefritis Agudas (abscesos o flemón perinefrítico).

Medicina. Marzo 1953

13. Neoplasia malignas renales.

Trazos. 1953

14. Divertículos de la uretra femenina. Dos casos.

Arch. Esp. Urol. IX, 2. 1953

15. Las anurias. Su tratamiento.

Revista Clínica Española. XLVIII, 1953

16. La radiografía simple de aparato urinario: Valor diagnóstico.

Revista Clínica Española. XV, II, 1. 1954 
17. Tumores de Testículo.

Trazos. 1954

18. Cistectomía Parcial por Megavejiga (enfermedad de Hirschprung).

Arch. Esp. Urol. XI, 4. 1955

19. Albuminuria Ortostática. Ptosis Renal derecha. Nefropexia. Curación.

Revista Clínica Española. LIX, 6. 1955

20. Falso tumor retroperitoneal (absceso perisigmoideo). Crisis de cólicos nefríticos en un niño de tres años.

Arch. Esp.Urol. XI, 4. 1955

21 . Abdomen agudo urológico.

Medicina. 1951

22. Tratamiento actual del cólico nefro-ureteral.

Trazos. 1956

23. Riñón único : operación de Boari.

Arch. Esp.Urol. XII, 1. 1956

24. Litiasis ureteral. Cólicos nefríticos. Cateterismo de uréter. Extravasación.

Arch. Esp. Urol. XII, 4. 1956

25. Riñón único. Ureterostomía cutanea. Absceso voluminoso intrarrenal.

Arch. Esp. Urol. XII, 4. 1956

26. Fibroadenoma de epidídimo.

Arch. Esp. Urol. XIV, 1. 1957

27. Torsión de la hidátide pediculada de Morgagni. Arch. Esp. Urol. XIV, 1. 1957

28. Tumor gigante paranefrítico.

Revista Clínica Española. LXXI, 3. 1958

29. La tuberculosis del epidídimo.

Medicina. 1958

30. Dos casos de uréter retrocava.

Boletín del Consejo General del Colegio de Médicos. 1959

31. Ruptura de uretra posterior. Un caso clínico. Arch. Esp. Urol. XIV, 2. 1959

32. Otro caso de divertículo uretral femenino.

Arch. Esp.Urol. XIV, 2. 1960

33. Operación de Boari-Casatti. Indicaciones, técnica. Presentación de un caso de fístula uretero-vaginal curado por dicha intervención.

Arch. Esp.Urol. XIV, 4. 1960

34. Riñón hipoplásico. Hipertensión. Nefrectomía. Revista Clínica Española. LXXVI, 4. 1960

35. Contusión abdominal izquierda. Rotura del riñón izquierdo. Fisura de bazo. $\mathrm{H}$ hemorragia intraperitoneal.

Arch. Esp. Urol. XV, 1. 1960

36. Quemadura de pene. Plastia escrotal. Dos casos. Arch. Esp. Urol. XV, 1. 1960

37. Deux cas d'uretere retrocave.

J. Urol. et Nephrol. 66, 5-6. 1960

38. Tumor raro renal. Adenocarcinosarcoma.

Revista Clínica Española. LXXXI, 5. 1961

39. Trasplante Renal (homotrasplante entre padre e hijo), en un caso de grave insuficiencia renal en riñón único congénito.

Medicamenta, 369. 1961

40. Problemas vasculares de los trasplantes renales. Angiología. XIII, 6. 1961

41. Estudio experimental de los autotrasplantes renales. Boletín del Consejo General de Médicos. 1961

42. Hidronefrosis tratada por la intervención de Hynes-Anderson.

Arch. Esp.Urol. XV, 4. 1961

43. Hematuria: Su valor semiológico.

Revista Clínica Española. LXXXIII, 5. 1961

44. Hipertrofia del cuello vesical en la mujer.

Arch. Esp. Urol. XVI, 1. 1962

45. Nefropatías unilaterales. Hipertensión. Presentación de dos casos.

Boletín de Patología Médica. II, 4. 1962

46. Carcinoma renal (cáliz superior del riñón izquierdo). Papanicolau.

Medicamenta. 383. 1962

47. Riñón poliquístico. Presentación de seis casos.

Boletín del Consejo General de Médicos. XXV, 163. 1962

48. Transplantation renale (homotransplantation entre pere et fils) pour grave insufisance fonctionelle d'un rein unique congenite.

J. Urol. et Nephrol. 68, 6. 1962 
49. Problemes vasculaires des transplantations renales. J. Urol. et Nephrol. 68, 6. 1962

50. Riñón en herradura. Hidronefrosis del riñón izquierdo.

Anales del Hospital de la Sta. Cruz y San Pablo. 1962

51. Observaciones de células neoplásicas en sangre periférica. Un caso de carcinoma renal.

52. Plastias intestinales (lleo y colocistoplastias)

Boletín del Colegio de Médicos. 1963

53. Abdomen agudo (falso abdomen agudo) por cálculo piélico radiotrasparente del riñón izquierdo.

Arch. Esp. Urol. XVIII, 2. 1965

54. Quiste parapiélico (riñón izquierdo).

Arch. Esp. Urol. XIX, 2. 1966

55. Policitemia e hidronefrosis (tres casos).

Medicamenta. XXIV, 432. 1966

56. Riñón en Herradura.

Arch. Esp. Urol. XX, 4. 1968

57. Ectopia renal ilíaca : manifestaciones urinarias y extraurinarias

Medicamenta. 447, 15. 1968

58. Riñón en herradura y litiasis

Arch. Esp. Urol. XX, 4, 1968

59. Tratamiento de las infecciones urinarias con sulfato de gentamicina.

Münchener Medizinische Wochenschrift. 110:9. 1968

60. Técnica radio-urológica: Pielografía percutánea. Medicamenta, XXVII, 459. 1969

61. Divertículos vesicales. Diverticulectomía.

Hospital General. IX, 1. 1969

62. Autotraumatismo de pene. Reconstrucción y resultados.

Congreso hispano-portugués de Urología. 1969

63. Mixosarcoma de vejiga en un hombre de sesenta y nueve años.

Congreso hispano-portugués de Urología. 1969

64. Tumores renales malignos en la infancia: tumor de Wilms. Neuroblastoma.

Hospital General. X, 2. 1970

65. Tumores renales. Valor diagnóstico.

Medicamenta. LIV, 476. 1970
66. Los córticosteroides en Urología y Nefrología.

Medicamenta. XLIII, 412. 1970

67. Incontinencia post-adenomectomía. Modificación a la técnica de Beneventi.

Medicamenta. XXIX, 483. 1971

68. Espacio retroperitoneal: valor clínico.

Medicamenta. XXX, 497. 1972

69. El dolor en Urología.

Medicamenta. XXX, 498. 1972

70. Quiste dermoide de ovario y uropatía obstructiva bilateral.

Congreso Nacional de Urología 1976

71. El uréter como complicación eventual en cirugía. Hospital General. XVI, 1. 1976

72. La cistectomía total en el cáncer de la vejiga urinaria.

Hospital General. XVII, 3. 1977

73. Diverticulosis uretrovaginal.

Toko-Ginecología Práctica. XXXVII, 413. 1978

74. Hidronefrosis por estenosis congénita de la unión ureteropiélica.

Arch. Esp. Urol. XXXIV, 3.1981

\section{BIBLIOGRAFIA Y LECTURAS

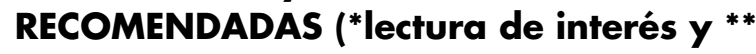 lectura fundamental)}

1. AGUILAR CABALlERO I.: "Discurso de fin de carrera ( Promoción 1940-45 )". Charlas Radiofónicas y Discursos, Madrid, Librería Editorial Científico Médica Española, pp. 87-108.

2. ALCALÁ-SANTAELLA, F.: "Pasado, presente y futuro de la Urología”. Discurso de recepción del académico electo Dr. D. Felipe Alcalá-Santaella, Real Academia de Medicina de Valencia, 1969.

3. ALFÉREZ VILLALOBOS, C.; BATALLA SABATÉ, L.; CIFUENTES DELATTE, L. y cols.: Actas Urol. Esp. Número Extraordinario L Aniversario de la Asociación Española de Urología, 1985.

4. FABRE, P.: "La Urología de ayer, de hoy y de mañana". Conferencia pronunciada en el Servicio de Urología del Hospital de la Princesa de Madrid, el día 4 de octubre de 1949. 
5. GARCÍA SÁNCHEZ, M.: "Evolución histórica del tratamiento de las obstrucciones del cuello vesical". Discurso para la recepción pública del Académico electo Ilmo. Sr. D. Manuel García Sánchez, Real Academia de Medicina y Cirugía de Galicia ( La Coruña ), 1973.

6. GIL-VERNET, J.M ${ }^{\mathrm{a}}$.: "Avances en Urología en los últimos 10 años”. Tiempos Médicos, 220: 69, 1982.

7. INSAUSTI CORDÓN, J.L.: "Madrid, Pulido, Hospital General". Hospital General, 20: 121, 1980.

8. INSAUSTI CORDÓN, J.L: "Compendio Histórico de la Urología Española y de su Asociación". Ponencia al IV Congreso Iberoamericano de Urología y XLVII Congreso Español de Urología, Acapulco (México), 1982.

9. LEIVA, O.; DUSKO, J.: "Alfonso de la Peña Pineda ( 1904-1971 )”. Urol. Integr. Invest., 7: 220, 2002.

10. MAGANTO PAVÓN, E.: "La Urología en Madrid". E. Maganto Pavón, Pérez Albacete (Coordinadores), Oficina de Historia de la Asociación Española de Urología, Historia Biográfica y Bibliográfica de la Urología Española en el siglo XX, Madrid, Edicomplet, pág. 221-282, 2002.

11. MONTERO, J.: "Fundación de la Sociedad Española de Urología". Actas del Segundo Congreso Español de Historia de la Medicina. Vol. I. Salamanca, 221-223, 1965.

12. PEÑA PINEDA, A.: "Epistemología Urológica (evolución de un saber)". Discurso para la recepción pública del Académico electo Excmo. Sr. D. Alfonso de la Peña Pineda. Real Academia Nacional de Medicina. Madrid, 1968.

13. PEÑA PINEDA, E.: "Medio siglo de Urología". Reun. Reg. Urol., XV: 163-171, 1972.
14. PÉREZ-IREZABAL Y ANDRÉS, J.: "Concepto y contenido actual de la Urología”. Forum al Congreso Español de Urología, Granada, Actas de la Asociación Española de Urología, VII(2): 7-22, 1972.

15. PÉREZ CASTRO, E.; PUIGVERT GORRO, A.; CIFUENTES DELATTE, L.: "Primeras Palabras". Arch. Esp. Urol., I: 6, 1944.

16. PÉREZ-CASTRO ELLENDT, E.: "La nueva Urología”. Arch. Esp. Urol., 43: 439, 1990.

17. PÉREZ ALBACETE, M.: "La enseñanza de la Urología en España en la primera mitad del siglo XX”. Urol. Integr. Invest., 7: 191, 2002.

18. PÉREZ ALBACETE, M.: "100 Figuras de la Urología Española”. Oficina de Historia de la Asociación Española de Urología, Mariano Pérez Albacete, 2005.

19. PEREIRA SANZ, I.: "Hospital de la Princesa y D. Luis Cifuentes". Actas Urol. Esp., Monográfico dedicado al Dr. Luis Cifuentes Delatte, XXX: 67-70, 2006.

20. PUIGVERT GORRO, A.: "Del saber y del hacer urológico". Conferencia de ingreso en la Sociedad Española de Médicos Escritores, 1976.

21. SÁNCHEZ GRANJEL, L.: "Retablo Histórico de la Urología Española". Salamanca, Instituto de Historia de la Medicina Española. Real Academia de Medicina de Salamanca, 1986.

22. VELA NAVARRETE, R.: "Luis Cifuentes : De cistitis y cistopatías (1947) a composición y estructura de los cálculos renales (1984)". Urol. Integr. Invest., 7: 187, 2002.

23. VELA NAVARRETE, R.: "Luis Cifuentes y su escuela. Datos biográficos de un extraordinario hombre de ciencia, urólogo y académico". Actas Urol. Esp. Monográfico dedicado al Dr. Luis Cifuentes Delatte, XXX : 1-5, 2006. 